ESSAY

\title{
Protecting a displaced species in an altered river: a case study of the endangered Sacramento River winter-run Chinook Salmon
}

\author{
ERICA M. MEYERS*
}

California Department of Fish and Wildlife, Fisheries Branch, P.O. Box 944209, Sacramento, CA 92444-2090, USA

*Corresponding Author: erica.meyers@wildlife.ca.gov

Endangered Sacramento River winter-run Chinook Salmon (Oncorhynchus tshawytscha) exist as a single population that spawns in the Sacramento River downstream of Shasta Dam near Redding, CA. Displaced from their historical habitat after dam construction circa 1940, their survival depends on cold water released from Shasta Reservoir. Managing and recovering the species is further complicated by their anadromous life history, habitat loss and degradation, largescale water supply management, and climate change. The California Department of Fish and Wildlife and other resource agencies coordinate closely to protect the species from extinction, confronting challenges with collaborative restoration and science-driven management. As climate change brings more frequent droughts, warmer weather, and increased variability in precipitation, Sacramento River winter-run Chinook Salmon recovery will require greater collaboration and a shift to more holistic restoration actions that promote and maintain the diversity and resilience of the species and its habitats.

Key words: California, CESA, Chinook Salmon, climate change, displaced species, endangered species, recovery, reintroduction, restoration, winter-run

Threatened and endangered species management is frequently complicated by ongoing anthropogenic impacts, such as continued habitat modification, pollution, and interactions with invasive species. Chinook Salmon (Oncorhynchus tshawytscha) in the Central Valley of California (Central Valley), which include four distinct runs named for the season when adults return to freshwater to spawn, share these threats. Their status and management are stymied by diverse anadromous life histories, harvest, large ranges, and highly altered, fragmented river systems. Climate change and extreme year-to-year variability in precipitation create additional challenges. Resource agencies, including the California Department of Fish and Wildlife (CDFW), National Marine Fisheries Service (NMFS), U.S. Fish and Wildlife Service (USFWS), State Water Resources Control Board (SWRCB), California Department of Water Resources (CDWR), and the U.S. Bureau of Reclamation (USBR), confront these challenges with applied science, adaptive management, and interagency collaboration to 
protect and enhance Central Valley salmon populations and their habitats. Yet for every successful recovery action, new challenges emerge for California salmon.

This struggle is particularly noteworthy for Sacramento River winter-run Chinook Salmon (winter-run Chinook Salmon), which have experienced both some of the greatest challenges and some of the greatest recovery successes. Winter-run Chinook Salmon historically spawned in the upper reaches of Sacramento River tributaries, including the McCloud, Pit, and Upper Sacramento rivers, and Battle Creek (Figure 1). These cold, spring-fed streams provided vital habitat for this species whose life history is otherwise poorly suited for the hot, dry summers of the Central Valley (Yoshiyama et al. 2001). In fact, the life history strategy of winter-run Chinook Salmon, which begin migration in winter but delay spawning until summer, is unique within the range of Chinook Salmon (Hallock and Fisher 1985; Moyle 2002). When USBR constructed Shasta Dam (1938-1945) and Keswick Dam (1941-1950) for the Central Valley Project, they blocked access to almost all historical spawning habitat and the ecoregion where winter-run Chinook Salmon evolved. A single population remains, spawning in the mainstem Sacramento River between Balls Ferry Bridge near Anderson, California (river km 444), and Keswick Dam (river km 486) (Figure 1), and its survival depends on an altered hydrologic regime and careful water management (NMFS 2014).

Winter-run Chinook Salmon, like all Pacific salmon (Onchorynchus spp.), are anadromous, meaning they are born in freshwater before spending most of their lives in saltwater and returning to freshwater to spawn. Adult winter-run Chinook Salmon leave the Pacific Ocean and enter San Francisco Bay beginning in December, continuing upstream through July (Moyle 2002). Over 90\% of winter-run Chinook Salmon spawn at age three; however, some will return as two-year-old "grilse" or at age four or five (USFWS 2013; Satterthwaite

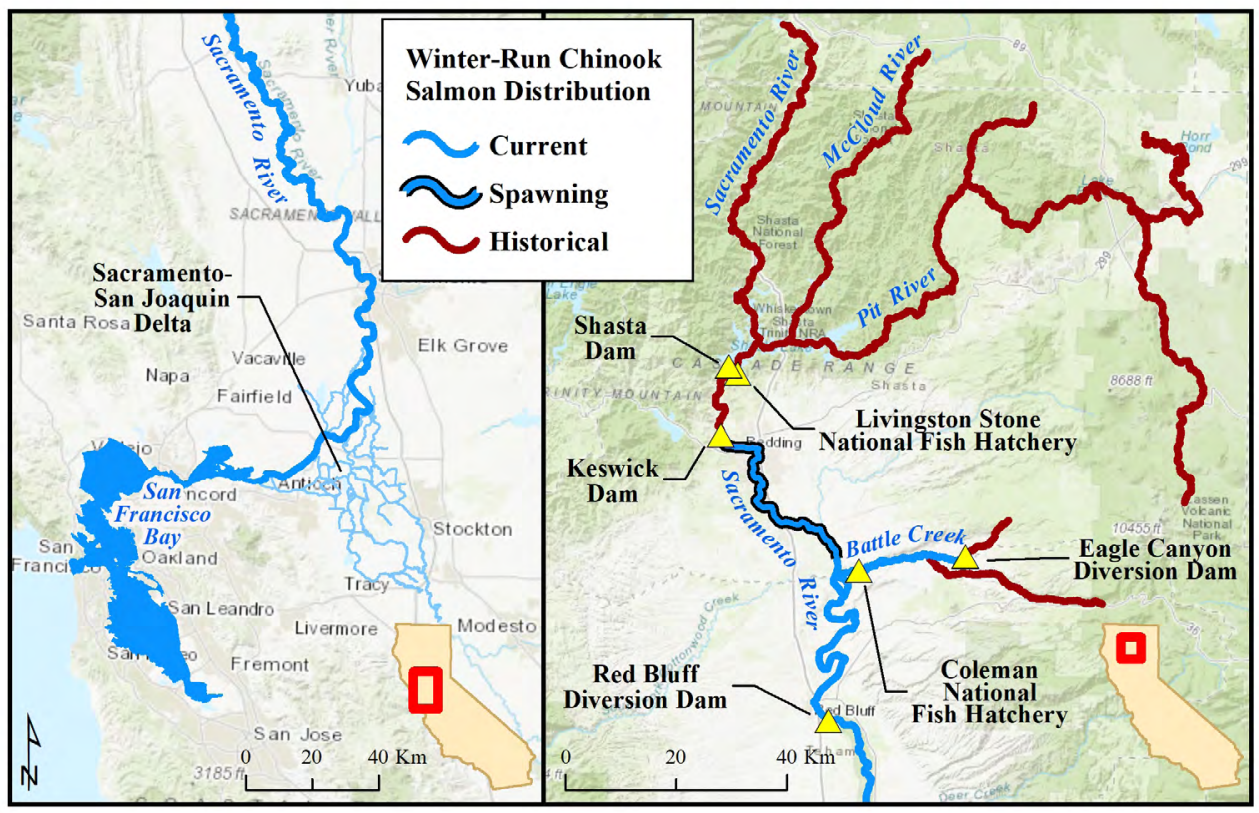

Figure 1. Map of historical and existing winter-run Chinook Salmon habitat in the Sacramento River basin and estuary. Data Sources: Yoshiyama et al. 2001; NMFS 2014 
et al. 2017). Spawning and egg incubation occur during the warmest time of the year and require gravel-bedded stream reaches with cold, clean water to support developing embryos from April through October (NMFS 2014). Juveniles rear and migrate downstream from July through March, reaching the Sacramento-San Joaquin Delta (Delta) from December through May (Figure 1) (NMFS 2014). Residence time in the Delta is variable, and juveniles may spend one to four months rearing prior to entering San Francisco Bay on their way to the Pacific Ocean (del Rosario et al. 2013). Because, in part, of this complex life history with long migrations and variable habitat needs at different life stages, winter-run Chinook Salmon have been the object of considerable research and more monitoring than many other imperiled species.

\section{Unlikely Success Before Decline And Listing}

Although far removed from their native range in the high-elevation, volcanic, springfed streams near Mt. Lassen and Mt. Shasta, winter-run Chinook Salmon initially did surprisingly well in the Sacramento River. After completion of Shasta and Keswick dams, they began spawning in the mainstem river below Keswick Dam, where the water released from Shasta Reservoir provided cool temperatures throughout the summer. Tens of thousands of winter-run Chinook Salmon returned to the Sacramento River for several generations, but the population began declining in the 1970s (Hallock and Fisher 1985), and annual escapement (i.e., the number of returning spawners each year) remained under a few thousand fish through the 1980s and 1990s (Figure 2). Escapement declined from nearly 120,000 spawners in 1969 (Moyle 2002) to a low of 144 spawners in 1994 (Azat 2020).

The primary factors driving the decline in winter-run Chinook Salmon since the 1970s are large dams, agricultural diversions, warm water temperatures, and habitat loss and degradation (NMFS 2014). Maintaining adequate river temperatures throughout the

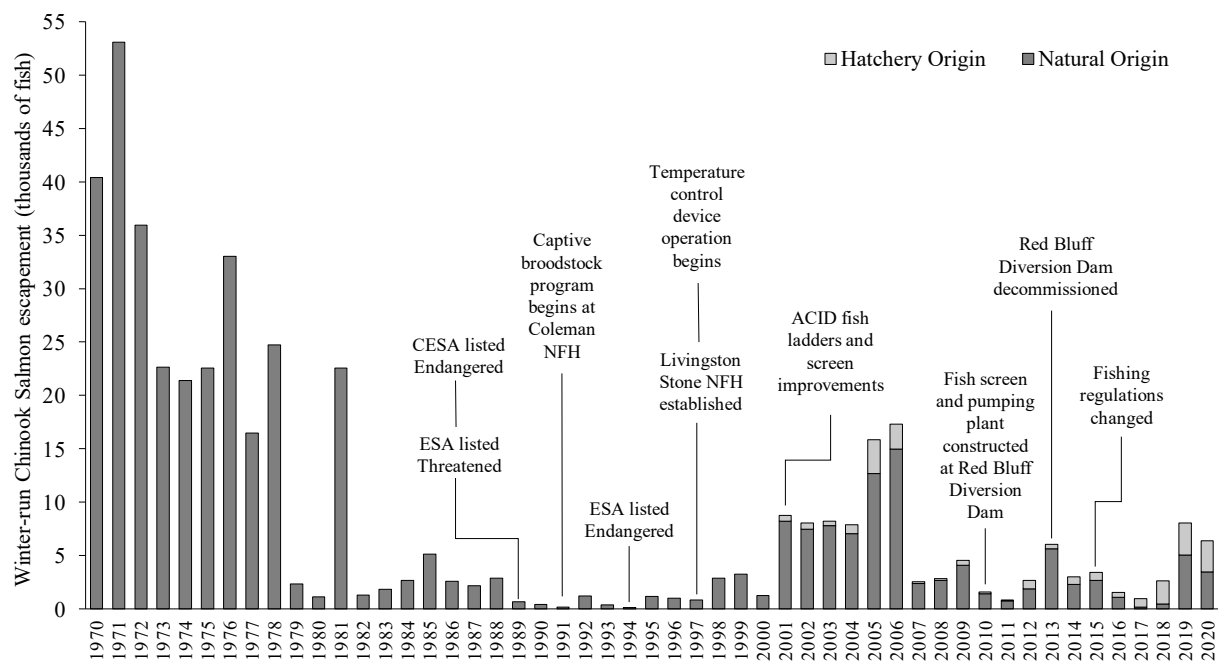

Figure 2. Sacramento River winter-run Chinook Salmon escapement (i.e., number of adult spawners) from 1970 to 2020 and notable recovery actions. NFH=National Fish Hatchery; ACID=Anderson Cottonwood Irrigation District 
spawning and incubation period requires deliberate management of the cold-water pool behind Shasta Dam, and the population has been highly reliant on hatchery production in some years when cold water is limited. Changes in the riverine and estuarian habitat affecting the species include major ecological shifts in the Delta ecosystem (Mahardja et al. 2017), increased water exports from the state and federal water projects, entrainment into water supply diversions, high predation rates (Moyle 2002), degraded water quality, and meteorological and hydrological changes (Williams et al. 2020). Furthermore, over 95\% of historical floodplain habitat in the Central Valley, which is important for juvenile rearing and could have buffered other ecological shifts, has been leveed and drained for flood control or conversion to agriculture (Herbold et al. 2018). In what was historically an expansive estuary and nursery for rearing Chinook Salmon, only 3\% of historical tidal wetland remains in the Delta, mostly as thin strips along the margins of levees (Whipple et al. 2012).

In 1989, after almost two decades of population decline, the California Fish and Game Commission listed winter-run Chinook Salmon as endangered under CESA(CA Fish and Game Commission 1989), and NMFS listed them as threatened under ESA (50 C.F.R. 17.11). The winter-run Chinook Salmon evolutionarily significant unit (ESU) was the first "distinct population segment" to be listed under the ESA, prior to a formal definition of ESU and subsequent NMFS policy development (Waples 1995). NMFS uses the ESU concept to determine whether a population or group of populations will be considered a "species" for the purposes of ESA (Waples 1991), and CDFW has generally adopted the same definition for making listing decisions for California salmon under CESA (e.g., CDFG 1998, 2002). In 1994, NMFS “up-listed" winter-run Chinook Salmon to endangered under the ESA, based on the continued decline of the species, weak expected returns, and continuing threats to the population (59 C.F.R. 440). Under the direction of NMFS, the Sacramento River WinterRun Chinook Salmon Recovery Team published the first Recovery Plan in 1996 (NMFS 1996), which evaluated impacts and prioritized restoration actions to recover the species.

Because they exist as a single, isolated population, winter-run Chinook Salmon are at greater risk of extinction. For the ESU to be resilient, it needs multiple spatially and genetically diverse populations that maintain long-term demographic processes and evolutionary potential (McElhany et al. 2000). It must also have redundancy, meaning there should be at least two or three viable independent populations that do not share the same extinction risks (Lindley et al. 2007). Assuming extinction risks are not correlated between populations, redundancy ensures that two populations are unlikely to go extinct simultaneously (McElhany et al. 2000). Without multiple independent populations, a single catastrophic event, such as an eruption of Mt. Lassen, a prolonged drought, or failure to successfully manage cold water storage in Shasta Reservoir, could result in extinction of the ESU (Lindley et al. 2007).

\section{Protecting and Recovering Winter-run Chinook Salmon}

Recovery actions for winter-run Chinook Salmon in the Sacramento River have been implemented through interagency collaboration, cooperative agreements, and regulatory actions by NMFS through the ESA (e.g., Biological Opinions) and the SWRCB, under its Water Code $\S 275$ authority to amend water rights permits and licenses to protect public trust uses (e.g., Order 90-5). NMFS Biological Opinions (NMFS 2009, 2019) and, more recently, a CDFW Incidental Take Permit (CDFW 2020), limit losses of juvenile winter-run Chinook Salmon to state and federal water project pumping facilities in the south Delta using operational triggers tied to forecasted juvenile abundance. Regulatory and permitting actions 
under CESA, which authorize and limit losses incidental to otherwise lawful projects and activities, offer additional protections to winter-run Chinook Salmon in the river and estuary.

Flow and temperature management actions in the Sacramento River, which both threaten and sustain spawning winter-run Chinook Salmon and their eggs, occur at federally operated water projects. Consequently, preemption of state law by federal law limits CDFW's regulatory and enforcement authority under CESA. Interagency and stakeholder cooperation remains essential to protecting and recovering winter-run Chinook Salmon. Both informal and formal working groups evaluate restoration options, plan water management, and coordinate actions for monitoring and managing the species. For example, the Sacramento River Temperature Task Group assists USBR in meeting requirements of Order 90-5 (SWRCB 1990) and includes representatives from state and federal agencies who meet as often as weekly to plan water temperature management during the winter-run Chinook Salmon spawning and incubation period. Another interagency team of scientists reviews best available science and monitoring data to produce an annual Juvenile Production Estimate, a forecast of winter-run Chinook Salmon juvenile abundance in the Delta that is used to set limits for allowable losses at the state and federal water projects (O'Farrell et al. 2018; NMFS 2020). This collaborative, inclusive, science-driven approach to species protection and management has, so far, proven effective at responding to threats and protecting the population from extinction.

\section{Recovery Actions}

Since listing, most species recovery actions have focused on managing habitat and increasing natural production and survival in the Sacramento River and Delta. Actions include rehabilitating spawning and rearing habitat, establishing a conservation hatchery program, improving passage at barriers, screening water diversions, reducing losses during water project operations, managing river temperatures, and limiting ocean harvest (Figure 2).

Because the population was so small at the time of listing, artificial propagation was implemented quickly, and the USFWS began a captive broodstock program for winter-run Chinook Salmon at Coleman National Fish Hatchery on Battle Creek in 1991. The captive broodstock provided a reserve for genetic diversity and produced a modest number of juveniles to supplement natural production. The program was successful in producing fish to augment the natural population and maintaining a minimum level of genetic diversity. Unfortunately, most hatchery-origin winter-run Chinook Salmon returned to the hatchery or lower Battle Creek and did not contribute to the mainstem population. To encourage fish to instead return to the Sacramento River, the winter-run Chinook Salmon broodstock program was moved to its current location below Shasta Dam in 1997, with the establishment of Livingston Stone National Fish Hatchery (LSNFH).

Another high priority recovery action was improving water temperature management during the winter-run Chinook Salmon spawning and incubation season. Order 90-5 required the USBR to install a Temperature Control Device (TCD) in Shasta Reservoir and to operate Keswick and Shasta Dams to maintain water temperatures to sustain all runs of salmon in the Sacramento River (SWRCB 1990). The TCD was first operational in 1997, the same year LSNFH was established. It allows dam managers to selectively withdraw water from a range of reservoir depths to meet water temperature targets in the Sacramento River.

The decade following TCD installation saw promising population growth for winter-run Chinook Salmon. The natural log-transformed cohort replacement rate $(\ln \mathrm{CRR})$ (Equation 
1), an annual indicator of population growth from one generation to the next, was positive for 9 of 10 years between 1997 and 2006 (Figure 3). For a stable population, one would expect a $\ln$ CRR greater than zero in, on average, half of all years. The rapid population growth was a promising sign for recovery, and the increasing trend in escapement from one generation $\left(\mathrm{N}_{\mathrm{t}-3}\right)$ to the next $\left(\mathrm{N}_{\mathrm{t}}\right)$ from 1996 to 2003 is the longest consistent trend, positive or negative, in the period of record. These calculations assume an average generation time of 3 years (USFWS 2013; Satterthwaite et al. 2017).

Equation 1: $\ln (C R R)=\ln \left(\frac{N_{t}}{N_{t-3}}\right)$ where $N$ is the number of adult spawners in year $t$

Additional recovery actions, many of which were required by the NMFS 2009 Biological Opinion for operation of the state and federal water projects (NMFS 2009), aimed to improve habitat conditions and increase species resilience. These actions included managing water temperature and Shasta Reservoir storage to protect fish, enhancing spawning and rearing habitat in the Sacramento River, screening diversions, removing passage barriers, increasing access to historical floodplains, limiting losses of juveniles at the state and federal pumping facilities, and improving facilities and operations at LSNFH. Many of these projects have been completed (e.g., installing fish screens and improving passage at Red Bluff Diversion Dam and Anderson-Cottonwood Irrigation District Dam, reconnecting side-channels to provide juvenile rearing habitat), and others are in progress (e.g., improving connectivity and juvenile rearing habitat in the Yolo Bypass). Notably, NMFS also required that USBR and CDWR take steps to reintroduce winter-run Chinook Salmon to historical habitat above Shasta Dam and in Battle Creek (NMFS 2009), which would create two additional populations to increase resilience of the ESU and support species recovery (NMFS 2014).

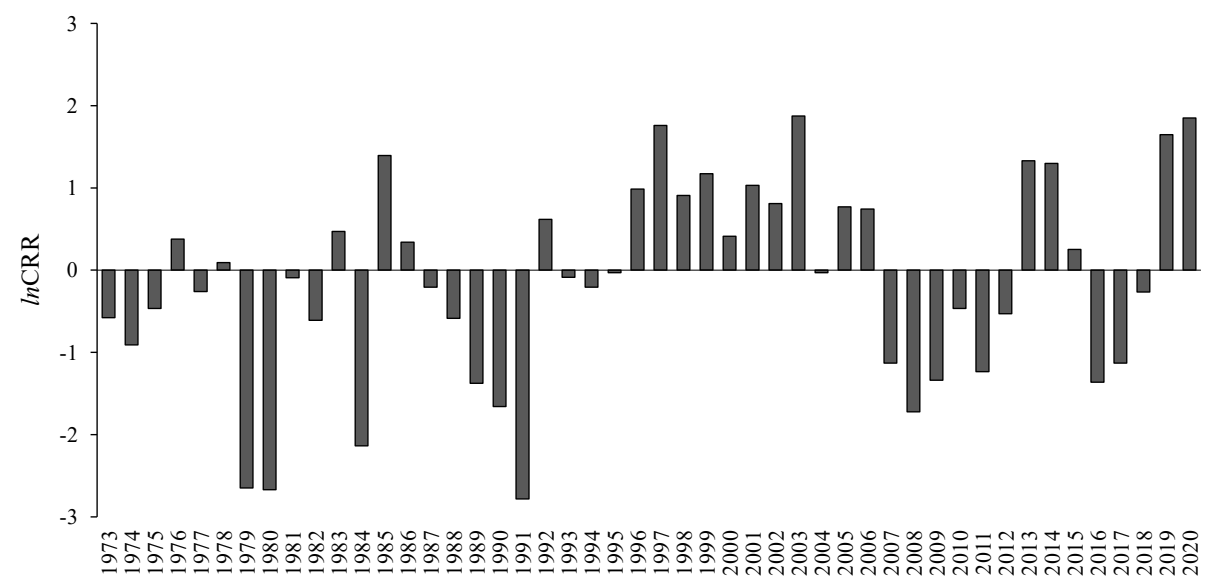

Figure 3. Natural $\log$ transformed cohort replacement rates, where $\ln (C R R)=\ln \left(\frac{N_{t}}{N_{t . s}}\right)$, and $N$ is the number of spawners in year $t$. 


\section{Responding to Crises}

With better managed water temperatures and habitat enhancements (e.g., adding spawning gravel below Keswick Dam), winter-run Chinook Salmon escapement in 2005 and 2006 reached numbers not seen since the 1970s; however, the perceived recovery was brief, as warm and unproductive ocean conditions off the California coast reduced survival of young salmon. All Pacific salmon runs suffered (Lindley et al. 2009), and winter-run Chinook Salmon escapement in 2007-2012 was as low as it had been in the late 1990s (Figure 2).

This period of poor ocean conditions was followed by a prolonged statewide drought from 2012-2016, which limited Sacramento River flows and the amount of cold water available for temperature management. In anticipation of poor survival of eggs and juveniles in the river, LSNFH tripled hatchery production in 2014 and 2015, while also reinitiating the captive broodstock program to create a genetic reserve. Winter-run Chinook Salmon experienced one genetic bottleneck in the 1990s (Lindley et al. 2007), and a second catastrophic loss could be more difficult to overcome. Despite efforts to forecast water temperatures and manage the cold-water pool, dam operators lost temperature control below Shasta Dam in August 2014, just as spawning completed and several months before all juveniles would emerge from the gravel (USBR 2015). The drought continued through the winter, and the cold-water pool the following year was even more limited. To extend the period of temperature control in 2015, fisheries resource agencies, water resource agencies, and water contractors negotiated and managed to a temporary temperature management target that was warmer and closer to Keswick Dam (NMFS 2015). Despite these efforts, an estimated 95\% of eggs in the river in 2014 and 2015 perished due to elevated water temperatures (Voss and Poytress 2017).

The temperature management target to protect winter-run Chinook Salmon eggs was $13.3^{\circ} \mathrm{C}\left(56^{\circ} \mathrm{F}\right)$, which is based on thermal tolerance estimates from controlled laboratory experiments (McCullough 1999; NMFS 2009). However, egg mortality in 2015 was much higher than predicted by the survival models, which assumed that temperatures lower than $13.3^{\circ} \mathrm{C}$ do not decrease survival. Martin et al. (2016) investigated this discrepancy and found that thermal tolerance in the river is approximately $3^{\circ} \mathrm{C}$ lower than in the laboratory, and egg and embryo mortality in the Sacramento River increases exponentially as water temperatures rise above $12^{\circ} \mathrm{C}\left(53.5^{\circ} \mathrm{F}\right)$. Lower inter-gravel flow velocities in the river limit oxygen supply and result in lower survival than estimated by the laboratory experiments (Martin et al. 2016). In response, NMFS revised temperature management targets to a daily average of $12^{\circ} \mathrm{C}$ at the compliance point, when achievable, and a secondary target of $13.3^{\circ} \mathrm{C}$ as part of a tiered approach to reduce temperature related egg mortality (NMFS 2019).

As winter-run Chinook Salmon struggled during the drought, CDFW and NMFS also took actions to reduce angling and harvest impacts on the species. In 2015 and 2016, CDFW recommended an emergency fishing closure from April through July for approximately $9 \mathrm{~km}$ of the Sacramento River upstream of Redding, CA, to prevent incidental harm to holding and spawning winter-run Chinook Salmon by anglers engaging in a very popular Rainbow Trout (O. mykiss) sport fishery in that river reach. The Fish and Game Commission adopted each of these temporary closures and, in 2017, permanently closed the area to fishing between 1 April and 31 July, pending information showing winter-run Chinook Salmon populations had improved to a level at which that reach could be reopened to fishing (CA Fish and Game Commission 2017).

In 2015, 2016, and 2017, CDFW, stakeholders, and the Pacific Fishery Management 
Council (PFMC), which manages ocean fisheries off the coast of California, Oregon, and Washington, recommended protective measures beyond those required under the ESA (B. Kormos, CDFW, personal communication). Because winter-run Chinook Salmon ocean distribution is generally farther south than more abundant fall-run Chinook Salmon (Satterthwaite et al. 2013), the recommended actions limited commercial and recreational ocean fisheries from San Francisco, CA, south to minimize contact with winter-run Chinook Salmon. In 2017, the PFMC and stakeholders recommended, and NMFS adopted, a new ocean harvest control rule to protect winter-run Chinook Salmon and to be more responsive to sudden reductions in production. The rule reduces the allowable impact rate based on projected escapement absent fishing. Reductions to the impact rate are typically achieved through size limits and time-area closures, allowing for minimal ocean fishing opportunities at low abundances (PFMC 2017).

\section{Opportunity for Reintroduction}

When captive broodstock at LSNFH sexually matured in 2017, the drought was ending, and hatchery production had returned to typical levels. Juveniles produced from captive broodstock provided an opportunity to begin small-scale pilot reintroduction into historical habitat in Battle Creek. In early 2018, tagged and marked winter-run Chinook Salmon were released into North Fork Battle Creek. The first fish returned in 2019 as two-year-old grilse. In 2020, more than 700 adults from the 2018 release returned to Battle Creek, and USFWS documented successful natural reproduction during juvenile monitoring (USFWS 2020). The return and successful spawning of these first winter-run Chinook Salmon in Battle Creek is a promising sign for success of the full-scale reintroduction, after completion of fish passage and flow actions in North Fork Battle Creek as part of the Battle Creek Salmon and Steelhead Restoration Project (Kier Associates 1999; ICF International 2016). The return of winter-run Chinook Salmon to Battle Creek marks an important milestone in the long-term collaborative efforts to achieve the recovery objectives of population diversity and redundancy (NMFS 2014).

\section{Emerging Challenges}

Tripling hatchery production at LSNFH reduced the immediate impact of the drought on juvenile production, but it presented different risks to the population. Increasing hatchery production from approximately 200,000 to 600,000 juveniles could lead to hatchery domestication (Araki et al. 2008) or reduce effective population size (Hedrick et al. 1995). When the juveniles from 2014 and 2015 brood years returned to the Sacramento River as adults, the proportion of hatchery-origin winter-run Chinook Salmon comprising the spawning population was three times higher than before the drought (Figure 4). To limit potential impacts of hatchery domestication selection on the natural population, the proportion of hatchery-origin spawners (pHOS) in the mainstem population should be less than 0.15 (Lindley et al. 2007). In 2017 and 2018, pHOS exceeded 0.8, which puts the population at a higher risk of extinction (Lindley et al. 2007).

Despite high proportions of hatchery spawners in the population, there are reasons to be optimistic. LSNFH uses conservation hatchery practices for propagation, carefully monitoring effective population size and using genetic testing to prevent introgression with other runs or using second-generation hatchery fish as broodstock (USFWS 2013). Also, pHOS and the proportion of hatchery-origin fish in hatchery broodstock (pHOB) have 

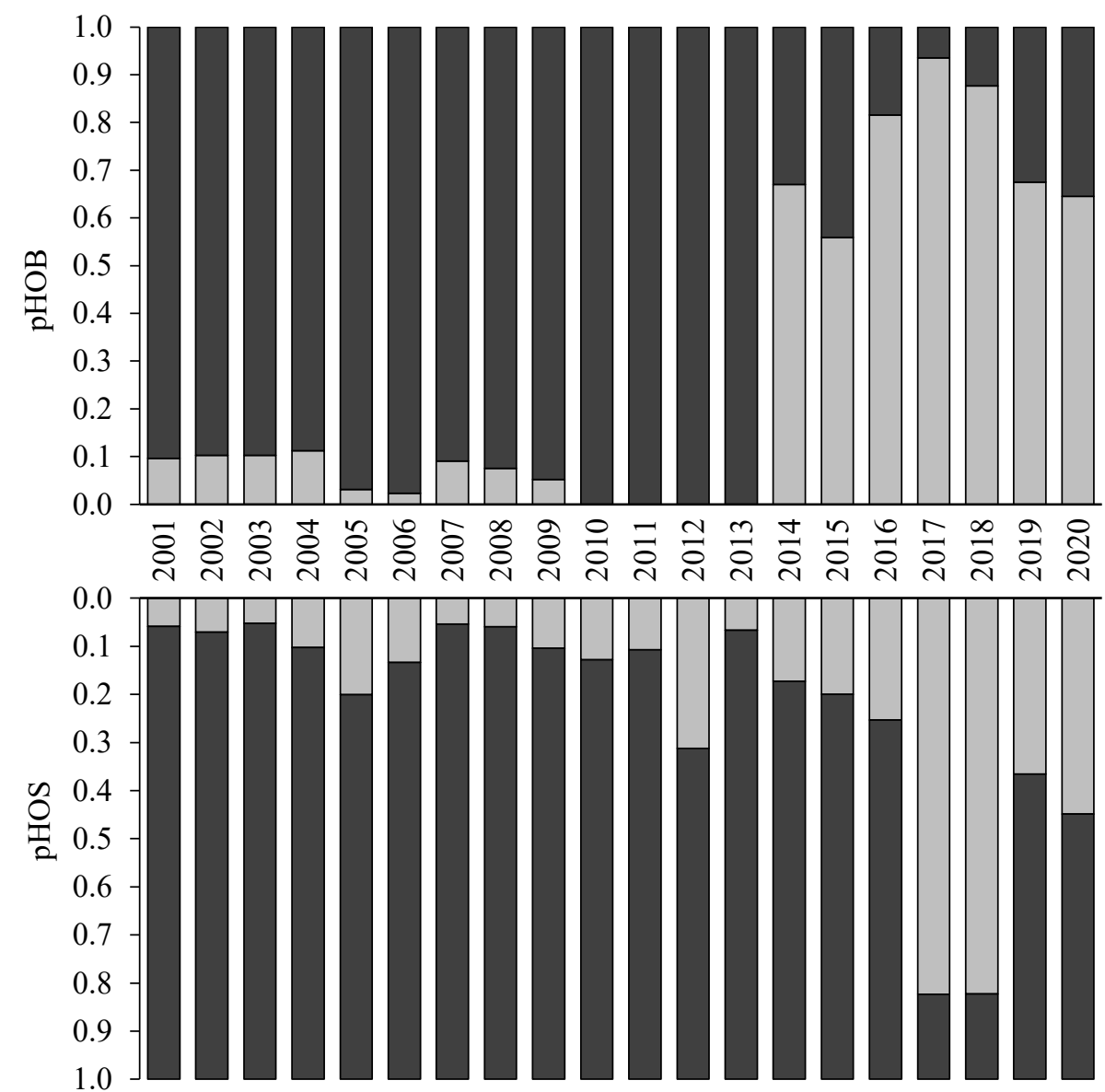

$\square$ Hatchery Origin $\square$ Natural Origin

Figure 4. Proportion of hatchery broodstock of hatchery origin (pHOB) (top) and proportion of in-river spawners of hatchery origin (pHOS) (bottom) from 2001 to 2020. To minimize risk of hatchery domestication, the population should have less than 0.15 pHOS (Lindley et al. 2007) and pHOB should be near zero. Data Sources: USFWS 2001, 2002, 2013; K. Gooding, USFWS, personal communication

been decreasing since 2017 (Figure 4). Perhaps most notably, data collected during carcass surveys suggest that escapement in 2017 and 2018 would have been among the five lowest on record without hatchery contribution. In 2017, only an estimated 151 of 975 (15.5\%) winter-run Chinook Salmon spawners were of natural origin (Figure 2). Progeny of the additional hatchery spawners that year contributed to the large number of spawners in 2019 and 2020, which are among the highest escapements in the last fifteen years (Azat 2020; D. Killam, CDFW, unpublished data).

To evaluate whether the high pHOS after the drought had population level effects, researchers at NMFS and the University of California, Santa Cruz, used genetic markers to assess reproductive success of hatchery-origin winter-run Chinook Salmon and their progeny. 
They found no evidence of survival differences between the offspring of hatchery-origin and wild parents, which indicates that domestication selection is either not occurring or is very weak in the population (Thompson 2018). This suggests that the short-term, emergency hatchery interventions taken during the drought were successful in conserving genetic diversity without reducing the overall fitness of the population. These findings contradict other monitoring that found evidence of reduced fitness in hatchery-origin winter-run Chinook Salmon in 2016 (Blankenship et al. 2019); however, the large numbers of returning adults in 2019 and 2020 suggest that any reduction in individual fitness did not have population level effects.

\section{The Future - Managing For Resilience}

Winter-run Chinook Salmon recovery actions have mostly focused on improving survival and responding to individual threats. While they have so far prevented extinction, species recovery in an era of climate change demands more holistic restoration actions to increase resiliency. Climate change is likely the greatest challenge for salmonids in California, particularly winter-run Chinook Salmon (Moyle et al. 2011). California's hydrology is expected to experience more variability, including more years of drought and greater swings between wet and dry conditions (Swain et al. 2018). Emerging science also suggests that North America is currently experiencing a "mega drought," a severe and persistent period of dry conditions (Mount 2020; Williams et al. 2020).

At the southern extent of Pacific salmon distribution, Central Valley Chinook Salmon evolved in a highly variable climate which included extended periods of drought and variable ocean conditions. Their resilience in such a dynamic environment is largely a result of habitat heterogeneity and life history diversity between and within populations (Herbold et al. 2018). Year-round cold water in high-elevation streams, extensive floodplains, and diverse and productive estuarine habitats buffered against temperature fluctuations and multi-decade droughts, which were common before 1850 but rare during the last century of dam building and water diversion (Herbold et al. 2018). Large dams that blocked access to rivers, simplified habitat, and reduced genetic and phenotypic diversity now limit the adaptive capacity of winter-run Chinook Salmon, making the species highly vulnerable to the effects of climate change (Crozier et al. 2019).

Water resources management, particularly temperature management, on the Sacramento River will continue to be essential for protecting winter-run Chinook Salmon and is expected to be more difficult in the future due to climate change (Crozier et al. 2019). The framework for effectively managing temperature exists in the annual temperature planning process (SWRCB 1990; NMFS 2009) and the ability to manipulate release temperature from Shasta Dam with the TCD; however, operational flexibility for water deliveries from Shasta Reservoir could provide additional survival benefits to winter-run Chinook Salmon during drier years. For example, recent analysis of historical data suggests that early season water temperatures affect spawn timing of winter-run Chinook Salmon, such that cooler temperatures in April and May result in earlier spawning peaks (Dusek Jennings and Hendrix 2020). If this is true, managed releases of cold water from Shasta Dam in the springtime could be used to encourage earlier spawning and increase egg survival in years when cold water is expected to be limited in the fall. It is important to consider, though, how this might impact later migrating winter-run Chinook Salmon and reduce phenotypic diversity in the population (e.g., Sturrock et al. 2019). Additionally, Chinook Salmon embryos are most 
sensitive to temperature later in development when oxygen demand is greater (Martin et al. 2020); therefore, a strategy of releasing cold water early in the season might not decrease overall egg mortality. More study is warranted to evaluate the implications of such a strategy on winter-run and other native fish in the Sacramento River basin.

Maintaining phenotypic and life history diversity, in concert with restoring habitat complexity and reconnecting migratory corridors, is essential to the resilience of Chinook Salmon in California (Herbold et al. 2018). Habitat heterogeneity not only distributes risk (Lindley et al. 2007; Schindler et al. 2015), but it also increases species resilience to habitat and climate change at the landscape scale (Brennan et al. 2019). Strontium isotope ratios in the otoliths of winter-run Chinook Salmon adults indicate that juvenile rearing strategies are more diverse than previously recognized. Approximately half of the adults sampled in 2007-2009 had reared as juveniles in tributaries to the Sacramento River and other non-natal habitats, many of which were not known to be demographically important to winter-run Chinook Salmon (Phillis et al. 2018). This finding supports previous observations of winterrun Chinook Salmon juveniles rearing in both large (PSMFC 2014) and small intermittent (Maslin 1996) tributaries to the Sacramento River. The variation in expression and success of different rearing strategies in winter-run Chinook Salmon is uncertain, but research on Central Valley fall-run Chinook Salmon indicates that successful rearing and migration strategies vary with hydrologic regime (Sturrock et al. 2015). Regulated stream flows (Sturrock et al. 2019) and warmer and drier hydrologic regimes (Munsch et al. 2019) can truncate migration size and timing, weakening the "portfolio effect" of phenotypic diversity that helps stabilize salmon populations. Maintaining and supporting diverse life history strategies within the population could increase winter-run Chinook Salmon resilience to climate change; however, actions favoring a narrow range of phenotypes could have negative evolutionary and demographic consequences (Sturrock et al. 2019).

Similarly, management actions to support the recovery of a single species can have implications for other species of concern (e.g., Alexander et al. 2018). For example, conserving cold water for winter-run Chinook Salmon spawning and egg incubation reduces environmental flows available to support outmigration of juvenile Central Valley springrun Chinook salmon, which are also at risk of extinction (Moyle et al. 2011) and listed as threatened under both the ESA and CESA. Federally threatened Green Sturgeon (Acipenser medirostris) embryos have a higher optimal temperature range than winter-run Chinook Salmon, and temperature management for winter-run Chinook Salmon in the Sacramento River has the potential to harm their development (Van Eenennaam et al. 2005; Poletto et al. 2018; Zarri et al. 2019). These types of trade-offs could be reduced by a transition from single-species management toward ecosystem-based management that supports multiple species and focuses on restoring physical and biological river processes (Poff et al. 1997), increasing habitat diversity, and reconnecting migratory corridors to historical spawning and rearing habitats (Herbold et al. 2018), and integrating management actions to maximize restoration benefits (Munsch et al. 2020). These types of landscape-scale restoration actions would increase habitat heterogeneity in time and space and increase the resilience of many native species, including Chinook Salmon, to climate change.

Winter-run Chinook Salmon are particularly vulnerable to climate change because they currently rely on managed cold-water releases from Shasta Reservoir. To maintain self-sustaining populations in a warming climate, winter-run Chinook Salmon need access to historical habitat in high-elevation, cold, spring-fed streams. Establishing an additional 
population in Battle Creek will provide population redundancy and reduce the extinction risk of the ESU (McElhany et al. 2003; Lindley et al. 2007; NMFS 2014). Given the greater likelihood of severe and persistent drought in the future (Swain et al. 2018), the existing population in the mainstem Sacramento River will likely require more frequent and greater hatchery intervention unless changes are made to water management or access is provided above Shasta Dam. Additional studies are necessary to determine how to best limit negative hatchery effects and the feasibility of reintroduction above Shasta Dam, such as the McCloud River reintroduction pilot project (CNRA 2017).

Winter-run Chinook Salmon management provides a unique case study in successful interagency cooperation to protect a species from extinction. Recovering the species to the point where they no longer need protection under the ESA and CESA will require continued collaboration to grow the population and expand their range by reconnecting historical habitat and establishing populations in streams that are less vulnerable to climate change. Effective management of winter-run Chinook Salmon during this time requires employing science advancements to improve life-stage monitoring (Johnson et al. 2017), adaptively managing reintroduction programs (ICF International 2016), and taking actions to maximize and preserve species and habitat diversity (Herbold et al. 2018). Continued commitment to collaborative stewardship, science-driven management, and holistic, landscape-scale restoration can, together, recover this iconic Central Valley species.

\section{ACKNOWLEDGMENTS}

Thank you to my colleagues at CDFW, including M. Johnson for early discussions about the manuscript and for technical review, D. Killam for carcass survey data, R. Kurth, J. Roberts, and J. Kelly for critical review, J. Brewster for mapping, and D. Kratville for sharing his knowledge and experience of winter-run Chinook Salmon management. Thank you also to K. Gooding (USFWS) for broodstock data, three anonymous reviewers and my Associate Editor for thoughtful recommendations, and K. Shaffer (CDFW) and M. Meyers (CDWR) for encouragement and editorial review.

\section{LITERATURE CITED}

Alexander, C. A. D., F. Poulson, D. C. E. Robinson, B. O. Ma, and R. A. Luster. 2018. Improving multi-objective ecological flow management with flexible priorities and turn-taking: A case study from the Sacramento River and Sacramento-San Joaquin Delta. San Francisco Estuary and Watershed Science 16(1)1-23.

Araki, H., B. A. Berejikian, M. J. Ford, and M. S. Blouin. 2008. Fitness of hatchery-reared salmonids in the wild. Evolutionary Applications 1(2):342-355.

Azat, J. 2020. California Central Valley Chinook population database report "GrandTab." California Department of Fish and Wildlife, Sacramento, CA, USA.

Blankenship, S., S. Zeug, and B. Cavallo. 2019. Broodyear 2016 winter-run vital rates study. Cramer Fish Sciences technical memo to Interested Parties. 20 December 2019.

Brennan, S. R., D. E. Schindler, T. J. Cline, T. E. Walsworth, G. Buck, and D. P. Fernandez. 2019. Shifting habitat mosaics and fish production across river basins. Science 364:783-786.

California Department of Fish and Game (CDFG). 1998. Status review of the spring-run 
Chinook Salmon (Oncorhynchus tshawytscha) in the Sacramento River drainage. Candidate Status Report 98-01. California Department of Fish and Game, Sacramento, CA, USA.

California Department of Fish and Game (CDFG). 2002. Status review of California Coho Salmon north of San Francisco. Report to the California Fish and Game Commission.

California Department of Fish and Wildlife (CDFW). 2020. California Department of Water Resources Incidental Take Permit No. 2081-2019-066-00 for long-term operation of the State Water Project in the Sacramento-San Joaquin Delta. Ecosystem Conservation Division, Sacramento, CA, USA.

California Fish and Game Commission. 2017. Fish and Game Commission Meeting. Rohnert Park, California. 26 April 2017.

California Natural Resources Agency (CNRA). 2017. Sacramento Valley Salmon Resiliency Strategy.

Crozier L. G., M. M. McClure, T. Beechie, S. J. Bograd, D. A. Boughton, M. Carr, T. D. Cooney, J. B. Dunham, C. M. Greene, M. A. Haltuch, E. L. Hazen, D. M. Holzer, D. D. Huff, R. C. Johnson, C. E. Jordan, I. C. Kaplan, S. T. Lindley, N. J. Mantua, P. B. Moyle, J. M. Myers, M. W. Nelson, B. C. Spence, L. A. Weitkamp, T. H. Williams, and E. Willis-Norton. 2019. Climate vulnerability assessment for Pacific salmon and steelhead in the California Current Large Marine Ecosystem. PLoSONE 14(7):e0217711.

del Rosario, R. B., Y. J. Redler, K. Newman, P. L. Brandes, T. Sommer, K. Reece, and R. Vincik. 2013. Migration patterns of juvenile winter-run-sized Chinook Salmon (Oncorhynchus tshawytscha) through the Sacramento-San Joaquin Delta. San Francisco Estuary and Watershed Science 11(1).

Dusek Jennings, E., and A. N. Hendrix. 2020. Spawn timing of winter-run Chinook Salmon in the Upper Sacramento River. San Francisco Estuary and Watershed Science 18(2):5.

Hallock, R. J., and F. W. Fisher. 1985. Status of winter-run Chinook Salmon, Onchorynchus tshawytscha, in the Sacramento River. Anadromous Fisheries Branch Office Report.

Hedrick, P. W., D. Hedgecock, and S. Hamelberg. 1995. Effective population size in winter-run Chinook Salmon. Conservation Biology 9:615-624.

Herbold, B., S. M. Carlson, R. Henery, R. C. Johnson, N. Mantua, M. McClure, P. Moyle, and T. Sommer. 2018. Managing for salmon resilience in California's variable and changing climate. San Francisco Estuary and Watershed Science 16(2):3.

ICF International. 2016. Battle Creek winter-run Chinook Salmon reintroduction plan. Prepared for the California Department of Fish and Wildlife, Sacramento, CA, USA.

Johnson, R. C., S. Windell, P. L. Brandes, J. L. Conrad, J. Ferguson, P. A. Goertler, B. N. Harvey, J. Heublein, J. A. Israel, D. W. Kratville, J. E. Kirsch, R. W. Perry, J. Pisciotto, W. R. Poytress, K. Reece, and B. G. Swart. 2017. Science advancements key to increasing management value of life stage monitoring networks for endangered Sacramento River winter-run Chinook Salmon in California. San Francisco Estuary and Watershed Science 15(3):1.

Lindley, S. T., R. S. Schick, E. Mora, P. B. Adams, J. J. Anderson, S. Greene, C. Hanson, B. P. May, D. R. McEwan, R. B. MacFarlane, C. Swanson, and J. G. Williams. 2007. 
Framework for assessing viability of threatened and endangered Chinook Salmon and steelhead in the Sacramento-San Joaquin Basin. San Francisco Estuary and Watershed Science 5(1):4.

Lindley, S. T., C. B. Grimes, M. S. Mohr, W. Peterson, J. Stein, J. T. Anderson, L. W. Botsford, D. L. Bottom, C. A. Busack, T. K. Collier, J. Ferguson, J. C. Garza, A. M. Grover, D. G. Hankin, R. G. Kope, P. W. Lawson, A. Low, R. B. MacFarlane, K. Moore, M Palmer-Zwahlen, F. B. Schwing, J. Smith, C. Tracy, R. Webb, B. K. Wells, and T. H. Williams. 2009. What caused the Sacramento River fall Chinook stock collapse? National Marine Fisheries Service Technical Memo NOAA-TMNMFS-SWFSC-447.

Mahardja, B. M. J. Farruggia, B. Schreler, and T. Sommer. 2017. Evidence of a shift in the littoral fish community of the Sacramento-San Joaquin Delta. PLoS ONE 12(1):e0170683.

Martin, B. T., P. N. Dudley, N. S. Kashef, D. M. Stafford, W. J. Reeder, D. Tonina, A. M. Del Rio, J. Scott Foott, and E. M. Danner. The biophysical basis of thermal tolerance in fish eggs. Proceedings of the Royal Society B 287:20201550.

Martin, B. T., A. Pike, S. N. John, N. Hamda, J. Roberts, S. T. Lindley, and E. M. Danner. 2016. Phenomenological vs. biophysical models of thermal stress in aquatic eggs. Ecology Letters 20(1):50-59.

Maslin, P. E., W. R. McKinney, and T. L. Moore. 1996. Intermittent streams as rearing habitat for Sacramento River Chinook Salmon. Anadromous Fish Restoration Program. Stockton, CA, USA.

McCullough, D. A. 1999. A review and synthesis of effects of alterations to the water temperature regime on freshwater life stages of salmonids, with special reference to Chinook Salmon. Prepared for the U. S. Environmental Protection Agency, Region 10. EPA 910-R-99-010.

McElhany, P., M. H. Ruckelshaus, M. J. Ford, T. C. Wainwright, and E. P. Bjorkstedt. 2000. Viable salmonid populations and the recovery of evolutionarily significant units. U.S. Department of Commerce. NOAA Technical Memo NMFS-NWFSC-42.

Mount, J. 2020. A path forward for California's freshwater ecosystems. Presentation to California Resources Agency. Public Policy Institute of California. 25 June 2020.

Moyle, P. B. 2002. Inland Fishes of California. University of California Press. Berkeley, CA, USA.

Moyle, P. B., J. V. E. Katz, and R. M. Quiñones. 2011. Rapid decline of California's native inland fishes: A status assessment. Biological Conservation 144(2011):2414 2423.

Munsch, S. H., C. M. Greene, R. C. Johnson, W. H. Satterthwaite, H. Imaki, and P. L. Brandes. 2019. Warm, dry winters truncate timing and size distribution of seaward-migrating salmon across a large, regulated watershed. Ecological Applications 29(4):e01880.

Munsch, S. H., C. M. Greene, R. C. Johnson, W. H. Satterthwaite, H. Imaki, P. L. Brandes, and M. R. O'Farrell. 2020. Science for integrative management of a diadromous fish stock: interdependencies of fisheries, flow, and habitat restoration. Canadian Journal of Fisheries and Aquatic Sciences 77:1487-1504.

National Marine Fisheries Service (NMFS). 1996. Recommendations for the recovery of the Sacramento River winter-run Chinook Salmon. Prepared by the Sacramento River winter-run Chinook Salmon Recovery Team under the supervision of the 
National Marine Fisheries Service, Southwest Region. 8 March 1996.

National Marine Fisheries Service (NMFS). 2009. Biological Opinion and Conference Opinion on the long-term operations of the Central Valley Project and State Water Project. West Coast Regional Office. 4 June 2009.

National Marine Fisheries Service (NMFS). 2014. Recovery plan for the evolutionarily significant units of Sacramento River winter-run Chinook Salmon and Central Valley spring-run Chinook Salmon and the distinct population segment of California Central Valley steelhead. California Central Valley Area Office.

National Marine Fisheries Service (NMFS). 2015. Contingency plan for Water Year 2015 pursuant to Reasonable and Prudent Alternative Action I.2.3.C of the 2009 Coordinated Long-term Operation of the Central Valley Project and State Water Project Biological Opinion, including a revised Sacramento River water temperature management plan. Letter to the U.S. Bureau of Reclamation and the California Department of Water Resources. 1 July 2015.

National Marine Fisheries Service (NMFS). 2019. Biological Opinion on long-term operation of the Central Valley Project and the State Water Project. West Coast Regional Office. 21 Oct 2019.

National Marine Fisheries Service (NMFS). 2020. Winter-run juvenile production estimates (JPE) for 2020. Letter to the U.S. Bureau of Reclamation. 3 Feb 2020.

O'Farrell, M. R., W. H. Satterthwaite, A. N. Hendrix, and M. S. Mohr. 2018. Alternative juvenile production estimate (JPE) forecast approaches for Sacramento River winter-run Chinook Salmon. San Francisco Estuary and Watershed Science 16(4):4.

Pacific Fisheries Management Council (PFMC) Ad Hoc Sacramento River Winter Chinook Workgroup. 2017. Further evaluation of Sacramento River winter Chinook control rules: addendum to Ad Hoc SRWC Workgroup (2017). PFMC Agenda Item kD.3.a SRWCW Report 1. November 2017.

Pacific States Marine Fisheries Commission (PSMFC). 2014. Juvenile salmonid emigration monitoring in the Lower American River, California, January-May 2014. Unpublished report prepared by J. Silva for the U.S. Fish and Wildlife Service and the California Department of Fish and Wildlife.

Phillis, C. C., A. M. Sturrock, R. C. Johnson, and P. K. Weber. 2018. Endangered winterrun Chinook Salmon rely on diverse rearing habitats in highly altered landscape. Biological Conservation 217:358-362.

Poff, N. L., J. D. Allan, M. B. Bain, J. R. Karr, K . L. Prestegaard, B. D. Richter, R. E. Sparks, and J. C. Stromberg. 1997. The natural flow regime. BioScience 47(11):769-784.

Poletto, J. B., B. Martin, E. Danner, S. E. Baird, D. E. Cocherell, N. Hamda, J. J. Jr. Cech, and N. A. Fangue. 2018. Assessment of multiple stressors on the growth of larval green sturgeon Acipenser medirostris: implications for recruitment of early lifehistory stages. Journal of Fish Biology 93(5):952-960.

Satterthwaite, W. H., S. M. Carlson, and A. Criss. 2017. Ocean size and corresponding life history diversity among the four run timings of California Central Valley Chinook Salmon. Transactions of the American Fisheries Society 146(4):594-610.

Satterthwaite, W. H., M. S. Mohr, M. R. O'Farrell, and B. K. Wells. 2013. A comparison of temporal patterns in the ocean spatial distribution of California's Central Valley Chinook salmon runs. Canadian Journal of Fisheries and Aquatic Sciences 70(4):574-584.

Schindler, D. E., J. B. Armstrong, and T. E. Reed. 2015. The portfolio concept in ecology 
and evolution. Frontiers in Ecology and The Environment. June 2015.

State Water Resources Control Board (SWRCB). 1990. Order 90-5. Order setting terms and conditions for fishery protection and setting a schedule for completion of tasks. State of California. Adopted 2 May 1990.

Sturrock, A. M., S. M. Carlson, J. D. Wikert, T. Heyne, S. Nusslé, J. E. Merz, H. J. W. Sturrock, and R. C. Johnson. 2019. Unnatural selection of salmon life histories in a modified riverscape. Global Change Biology 26:1235-1247.

Sturrock, A. M., J. D. Wikert, T. Heyne, C. Mesick, A. E. Hubbard, T. M. Hinkelman, P. K. Weber, G. E. Whitman, J. J. Glessner, and R. C. Johnson. 2015. Reconstructing the migratory behavior and long-term survivorship of juvenile Chinook Salmon under contrasting hydrologic regimes. PLoS One 10(5):e0122380.

Swain, D. L., B. Langenbrunner, J. D. Neelin, and A. Hall. 2018. Increasing precipitation volatility in twenty-first-century California. Nature Climate Change 8:427-433.

Thompson, N. 2018. What makes a successful hatchery fish? Using microhaplotypes to understand correlates of broodstock reproductive success in winter-run Chinook Salmon. Presentation to the Bay-Delta Science Conference, September 2018. Sacramento, CA.

U.S. Bureau of Reclamation (USBR). 2015. Shasta Temperature Management Plan Key Components. Transmittal to the State Water Resources Control Board. 18 June 2015.

U.S. Fish and Wildlife Service (USFWS). 2003. 2001 Annual report of winter Chinook propagation activities. Red Bluff Fish and Wildlife Office. April 2003.

U.S. Fish and Wildlife Service (USFWS). 2006. 2002 Annual report of winter Chinook propagation activities. Red Bluff Fish and Wildlife Office. June 2006.

U.S. Fish and Wildlife Service (USFWS). 2013. Hatchery and Genetics Management Plan for Livingston Stone National Fish Hatchery. 3 July 2013.

U.S. Fish and Wildlife Service (USFWS). 2020. 700 winter-run Chinook Salmon return to Battle Creek. Press Release. 22 October 2020.

Voss, S. D., and W. R. Poytress. 2017. Brood year 2015 juvenile salmonid production and passage indices at Red Bluff Diversion Dam. U.S. Fish and Wildlife Service, Red Bluff Fish and Wildlife Office.

Waples, R. S. 1991. Pacific salmon, Oncorhynchus spp., and the definition of "species" under the Endangered Species Act. National Marine Fisheries Service, Marine Fisheries Review 53(3)11-22.

Waples, R. S. 1995. Evolutionarily significant units and the conservation of biological diversity under the Endangered Species Act. American Fisheries Society Symposium 17:8-27.

Ward, M. B., and W. M. Kier. 1999. Battle Creek Salmon and Steelhead Restoration Plan. Prepared by Kier Associates for the Battle Creek Working Group.

Whipple, A. A., R. M. Grossinger, D. Rankin, B. Stanford, and R. A. Askevold. 2012. Sacramento-San Joaquin Delta historical ecology investigation: exploring pattern and process. Prepared for the California Department of Fish and Wildlife and Ecosystem Restoration Program. San Francisco Estuary Institute-Aquatic Science Center, Richmond, CA, USA.

Williams, A. P., E. R. Cook, J. E. Smerdon, B. I. Cook, J. T. Abatzoglou, K. Bolles, S. H. Baek, A. M. Badger, and B. Liveneh. 2020. Large contribution from an- 
thropogenic warming to an emerging North American megadrought. Science 368(6488):314-318.

Yoshiyama, R. M., E. R. Gerstung, R. W. Fisher, and P. B. Moyle. 2001. Historical and present distribution of Chinook Salmon in the Central Valley drainage of California. Contributions to the Biology of Central Valley Salmonids. Department of Fish and Game Fish Bulletin 179(1):71-176.

Zarri, L. J., E. M. Danner, M. E., Daniels, and E. P. Palkovacs. 2019. Managing hydropower dam releases for water users and imperiled fishes with contrasting thermal habitat requirements. Journal of Applied Ecology 00:1-10.

Submitted 12 October 2020

Accepted 13 November 2020

Associate Editor was F. Moye 